\title{
Formation of Isotactic Poly(methyl methacrylate) in Tetrahydrofuran by Butyllithium
}

\author{
Koichi Hatada, Mitsuru Furomoto, \\ Yoshihiro UMEMURA, and Heimei YUKI \\ Department of Chemistry, Faculty of Engineering Science, Osaka University, \\ Machikaneyama, Toyonaka, Osaka 560, Japan.
}

(Received September 5, 1979)

\begin{abstract}
KEY WORDS Slow-Growth Polymerization / Anionic Polymerization / Isotactic Poly(methyl methacrylate) / Butyllithium / Methyl Methacrylate / Tetrahydrofuran /
\end{abstract}

In the polymerization of methyl methacrylate (MMA) by butyllithium (BuLi) in a polar solvent such as tetrahydrofuran (THF), the growing chain ends are considered to be a single kind of propagation sites which produce a syndiotactic polymer by stereoregulation, similar to that in radical polymerization. In this work, we discovered the formation of isotactic polymer in the polymerization of MMA initiated with BuLi in THF, by using a slowgrowth polymerization technique. ${ }^{1-4}$

This slow-growth polymerization is a special method for ionic polymerization, wherein the initiator solution is slowly added to the monomer solution to enable it to rest on the top of it as a separate liquid phase and the polymerization is allowed to proceed without stirring (Figure 1). In this polymerization, the initiation occurs at the interface between the initiator and monomer solutions, and the polymerization reaction proceeds from top to bottom. After the polymerization has proceeded for a certain period of time, the polymerization vessel is cooled in liquid nitrogen and carefully broken. Then the reaction mass is sliced into three portions, designated as I, II and III from top to bottom. The polymers formed are isolated from each portion and characterized.

By the slow-growth method, we could obtain a polymer or copolymer different in tacticity, molecular weight or composition from that obtained by ordinary method. Poly(methyl methacrylate) prepared by the slow-growth method in toluene by BuLi had a higher isotacticity and molecular weight than the polymer obtained by the ordinary method. ${ }^{1,4}$

When the slow-growth polymerization of MMA was carried out in THF at $-78^{\circ} \mathrm{C}$, the stereoregularity of the polymer obtained was very close to that prepared by the ordinary method.* However, in the polymerization at $0^{\circ} \mathrm{C}$, it was surprising to find that a polymer containing more than $50 \%$ isotactic triads had been formed as shown in Table I. For instance, the polymer isolated from the top portion had a tacticity of $I, 68 \% ; H, 14 \% ; S, 18 \%$. An ordinary polymerization under the same condition gave, of course, a syndiotactic polymer. So, the difference in tacticity between the polymers prepared by these two methods is much remarkable in polymerization in THF at $0^{\circ} \mathrm{C}$.

Slow-growth polymerizations were carried out in THF by BuLi at various temperatures and the tacticities of the polymers were compared with those of the polymers prepared by the ordinary method

* The poly(methyl methacrylate) prepared by the slowgrowth method in THF with BuLi at $-78^{\circ} \mathrm{C}$ for $600 \mathrm{~h}$ in our previous work ${ }^{1}$ was not syndiotactic, but rather atactic. When the slow-growth polymerization was carried out in THF at $-78^{\circ} \mathrm{C}$ for $168 \mathrm{~h}$ in the presence of a small amount of water $\left(\left[\mathrm{H}_{2} \mathrm{O}\right] /[\mathrm{BuLi}]=0.4\right)$, the polymer formed contained a fairly large amount of heterotactic triads as follows.

The top layer: $I, 19 \% ; H, 42 \% ; S, 39 \%$. The second layer: $I, 13 \%, H, 43 \%, S, 44 \%$. The bottom layer: $I, 13 \% ; H, 43 \%$ $S, 44 \%$. The reason for the difference between the present and heretofore results may be the incidental small amount of water that existed in the reaction mixture in the previous work. 


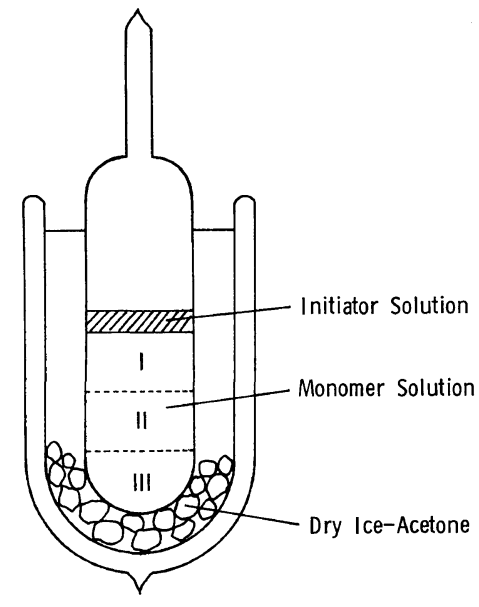

Figure 1. Slow-growth polymerization.

Table I. Slow-growth polymerization of methyl methacrylate in THF at $0^{\circ} \mathrm{C}$ for $24 \mathrm{~h}^{\mathrm{a}}$

\begin{tabular}{cccccc}
\hline & \multicolumn{2}{c}{ Yield } & & \multicolumn{3}{c}{ Tacticity $/ \%$} \\
\cline { 2 - 5 } \cline { 5 - 5 } & $\%$ & & $I$ & $H$ & $S$ \\
\hline I & 1.0 & & 68 & 14 & 18 \\
II & 3.3 & & 55 & 18 & 27 \\
III & 0.8 & & 54 & 19 & 27 \\
O $^{\mathbf{b}}$ & 15.5 & & 19 & 35 & 46 \\
\hline
\end{tabular}

a Monomer, $10 \mathrm{mmol}$; BuLi, $0.5 \mathrm{mmol}$; solvent, $10 \mathrm{ml}$.

b Polymerization by ordinary method.
(Table II). The fractions of isotactic triads in the polymer increased with an increase in the polymerization temperature in both polymerization methods. However, the extent of the increase in the fractions of isotactic triads was much more remarkable in the slow-growth polymerization, especially above $0^{\circ} \mathrm{C}$.

It has been reported that in the polymerization of MMA with BuLi in toluene, a small amount of lithium methoxide is formed through the reaction of the initiator with the carbonyl double bond of the monomer, and the methoxide is strongly related to the formation of syndiotactic sequences. ${ }^{5}$<smiles>COC(=O)/C=C(\C)C(=O)OC</smiles><smiles>C=C(C)C(=O)Br</smiles>

It was found, by using the perdeuterated monomer (MMA- $\mathrm{d}_{8}$ ), that the butyl isopropenyl ketone is incorporated into the polymer and oligomer chains as a comonomer. ${ }^{6}$ The amount of butyl isopropenyl ketone unit in the molecules of the polymer and oligomer of MMA- $d_{8}$ prepared by slow-growth method was lower than that in the polymer and oligomer obtained by the ordinary method, indicat-

Table II. Temperature dependence of the stereoregularity of poly(methyl methacrylate) prepared in THF by BuLi

\begin{tabular}{|c|c|c|c|c|c|c|}
\hline \multirow{3}{*}{$\begin{array}{c}\begin{array}{c}\text { Polymerization } \\
\text { temp }\end{array} \\
{ }^{\circ} \mathrm{C}\end{array}$} & \multicolumn{6}{|c|}{ Tacticity $/ \%$} \\
\hline & \multicolumn{3}{|c|}{ Ordinary method } & \multicolumn{3}{|c|}{ Slow-growth method ${ }^{b}$} \\
\hline & $I$ & $H$ & $S$ & $I$ & $H$ & $S$ \\
\hline-78 & 7 & 37 & 56 & 7 & 34 & 59 \\
\hline-20 & 15 & 35 & 50 & 17 & 26 & 57 \\
\hline 0 & 19 & 35 & 46 & 54 & 19 & 27 \\
\hline 30 & 22 & 35 & 43 & 57 & 15 & 28 \\
\hline
\end{tabular}

${ }^{\text {a }}$ Monomer, $10 \mathrm{mmol}$; BuLi, $0.5 \mathrm{mmol}$; THF, $10 \mathrm{ml}$; polymerization time, $24 \mathrm{~h}$.

b The values of tacticities represent those for the polymers formed in the third portion (bottom) of the reaction mixture. 
ing a lower extent of methoxide formation in the slow-growth polymerization. The reduced amount of lithium methoxide is considered to be one of the reason for the increase in the isotacticity in slowgrowth polymerization. ${ }^{4}$

The slow-growth polymerization of MMA- $d_{8}$ was carried out in THF with BuLi at $0^{\circ} \mathrm{C}$ for $168 \mathrm{~h}$. The ${ }^{1} \mathrm{H}$ NMR spectra of the polymer and oligomer formed clearly showed that the amount of the copolymerized ketone was much lower than that in ordinary polymerization. This may suggest that the decrease in the amount of lithium methoxide is also an important factor in the formation of isotactic sequences in the slow-growth polymerization in THF. An extensive study on this matter is now under way and the results will be published in near future.

\section{REFERENCES}

1. H. Yuki, K. Hatada, and S. Kokan, Polym. J., 5, 329 (1973).

2. K. Hatada, S. Kokan, and H. Yuki, J. Polym. Sci., Polym. Lett. Ed., 13, 721 (1975).

3. K. Hatada, M. Furomoto, and H. Yuki, Makromol. Chem., 179, 1107 (1978).

4. K. Hatada, M. Furomoto, T. Kitayama, Y. Tsubokura, and H. Yuki, Polym. J., 12, 193 (1980).

5. D. M. Wiles and S. Bywater, Trans. Faraday Soc., 61, 150 (1965).

6. K. Hatada, T. Kitayama, K. Fujikawa, K. Ohta, and H. Yuki, Polym. Bull., 1, 103 (1978). 